\title{
Methotrexate-induced malabsorption in children with acute lymphoblastic leukaemia
}

\author{
A W CRAFT, H E M KAY, D N LAWSON, T J MCELWAIN
}

British Medical fournal, 1977, 2, 1511-1512

\section{Summary}

A one-hour D-xylose absorption test was performed on 18 children with acute lymphoblastic leukaemia. Xylose absorption was normal in children who had not received methotrexate, but there was a significant degree of malabsorption in those who had taken methotrexate within the previous seven days. There was a progressive and significant increase in malabsorption related to the cumulative dose of methotrexate.

These findings provide further evidence that regular methotrexate treatment every seven days is more toxic than if it is more widely spaced. The spacing of treatment is currently under investigation.

\section{Introduction}

The folic acid antagonist methotrexate (Amethopterin) is widely used in the treatment of acute lymphoblastic leukaemia (ALL). ${ }^{12}$ Large doses damage the intestinal mucosa, and smaller amounts may cause oral ulceration. ${ }^{3}$ This damage may lead to malabsorption of both food and drugs from the small intestine. We have investigated this possibility in a group of children with ALL by using the one-hour D-xylose absorption test. ${ }^{*}$ We also examined the effects of the timing and duration of methotrexate treatment on xylose absorption.

\section{Patients and methods}

We studied 18 children with ALL, 17 boys and one girl, aged 2-11 years. Their weights ranged from 13 to $30 \mathrm{~kg}$. Ten were being treated according to the Medical Research Council UKALL V protocol ${ }^{5}$ and eight were on a Royal Marsden Hospital multidrug intensive protocol. Maintenance treatment for all the children included regular oral doses of methotrexate and mercaptopurine. The timing of treatment varied: some received it once every seven days, while others took it for four or five days out of every 21 . In both groups the treatment was occasionally delayed because of low blood counts.

A standard one-hour D-xylose absorption test was performed on 23 separate occasions, three children having two and one three tests, separated by five weeks or more. The tests were mainly performed on an outpatient basis. The children were allowed a drink on waking, and when they arrived at the hospital a fasting specimen of blood was taken and $5 \mathrm{~g}$ D-xylose dissolved in $100 \mathrm{ml}$ of water was given. A second blood specimen was taken one hour later and the D-xylose concentration measured. ${ }^{6}$ The difference between the fasting and onehour specimens was used for comparisons. Four children had the test performed during the initial stages of treatment before methotrexate treatment had begun. The remainder were carried out at varying intervals during the course of treatment.

Department of Paediatric Oncology, Royal Marsden Hospital, Sutton, Surrey SM2 5PT

A W CRAFT, MB, MRCP, senior registrar

H E M KAY, FRCP, FRCPATH, consultant haematologist

D N LAWSON, MD, FRCP, consultant paediatric oncologist

T J MCELWAIN, MB, FRCP, consultant physician

\section{Results}

The one-hour blood concentrations of $\mathrm{D}$-xylose in the children who had not received methotrexate, and in those who had received methotrexate seven days or between 14 and 28 days before the test are shown in fig 1 . The mean ages of the three groups were $3 \cdot 3,4 \cdot 9$, and 4.9 years, and their weights $16 \cdot 3,20$, and $21 \mathrm{~kg}$. The difference between those who had not received methotrexate and the group who had received it seven days before was significant $(P<0.01$; Student's $t$ test $)$.

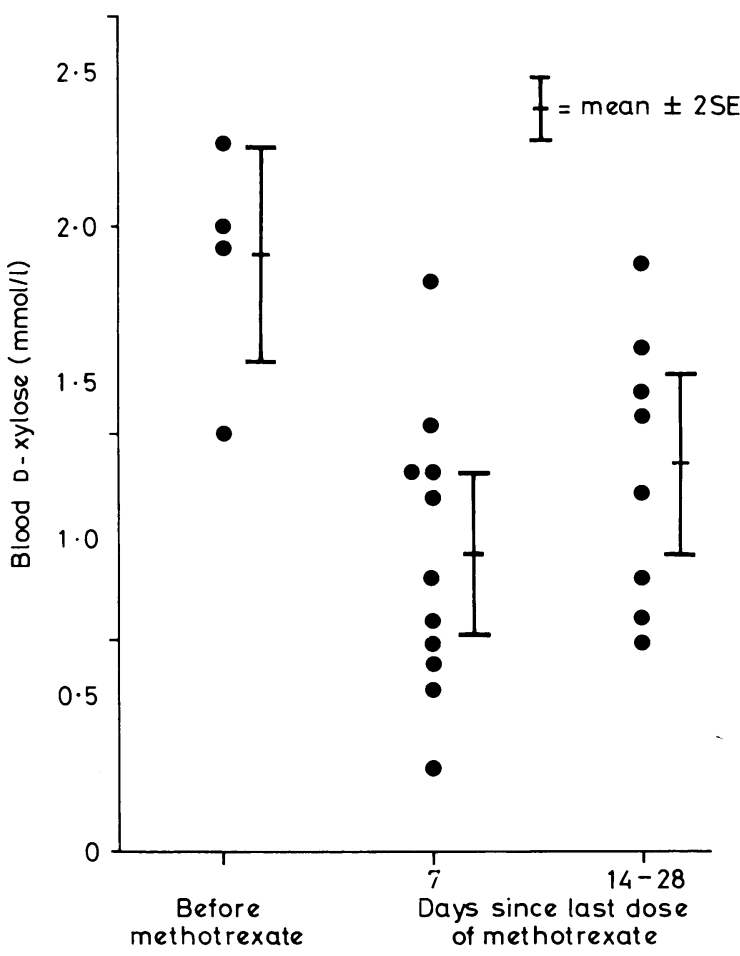

FIG 1-One-hour blood concentrations of $\mathrm{D}$-xylose in children who had not received methotrexate, and in those given methotrexate either seven days or between 14 and 28 days before the test.

Conversion: SI to traditional units-Xylose: $1 \mathrm{mmol} / 1 \approx$ $15 \mathrm{mg} / 100 \mathrm{ml}$.

Figure 2 shows the one-hour blood concentration of $\mathrm{D}$-xylose according to the total amount of methotrexate corrected for surface area) taken by the children during the course of treatment. The mean ages of the three groups were $3 \cdot 3,4 \cdot 5$, and $5 \cdot 4$ years, and their mean weights were $16.3,18.9$, and $22.6 \mathrm{~kg}$. The mean time since the previous dose of methotrexate in the group who had received up to $300 \mathrm{mg} / \mathrm{m}^{2}$ was 12 days, and in the other group was 13.5 days. The differences between the children who had not received methotrexate and the other two groups were both significant $(P<0.01)$, but the difference between the two groups who had received methotrexate was less significant $(P<0.02)$.

\section{Discussion}

The one-hour blood xylose test has been suggested as a useful screening test for malabsorption in untreated coeliac disease, a concentration above $1.3 \mathrm{mmol} / 1(20 \mathrm{mg} / 100 \mathrm{ml})$ usually exclud- 


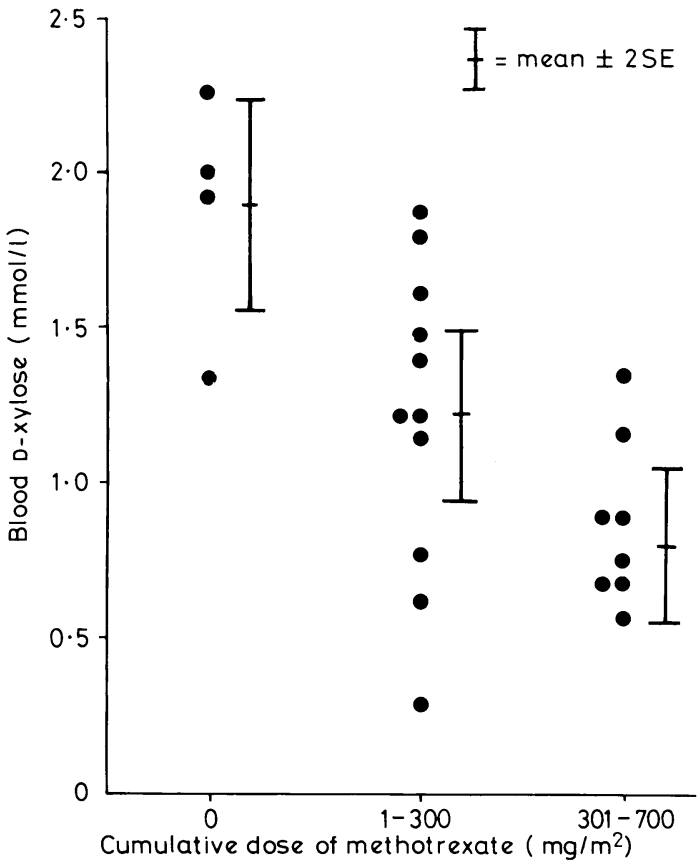

FIG 2-One-hour blood concentrations of D-xylose related to cumulative dose of methotrexate.

ing this diagnosis. Xylose absorption was normal in all four of the children who had not had methotrexate, but had received other cytotoxic drugs. Many of the other test results were abnormal, suggesting a degree of functional malabsorption. None of the children had any symptoms of malabsorption, although there was some slowing of growth. This, however, may have been partly due to mild growth-hormone deficiency after cranial irradiation.?

Rats given oral aminopterin, a closely related folic acid antagonist, develop a significant reduction in xylose absorption. Repeated administration of methotrexate to rats causes severe destruction of villi in the small intestine, and this eventually causes malabsorption of amino-acids. ${ }^{9}$ Trier $^{1011}$ has studied the morphological changes induced in the human small intestine by a single intravenous dose of methotrexate. Light microscopy showed only a reduction in the mitotic rate, but electron microscopy showed appreciable intracellular disruption.

The present study shows that repeated administration of oral methotrexate to children may cause a functional malabsorption of xylose. All the children were receiving other cytotoxic agents, and these may also have contributed to the presumed gastrointestinal damage. Nevertheless, the children who had not received methotrexate had normal xylose absorption, and intestinal absorption of xylose deteriorated progressively with increasing duration of treatment (fig 2). The spacing of the methotrexate dose seems to be important (fig 1), since those tested within the seven days of treatment had more severe malabsorption than those tested after 14 days. Seven days may be too short a time for the intestinal mucosa to recover from the previous insult. There was little difference in the mean interval between doses in the groups given more or less than $300 \mathrm{mg} / \mathrm{m}^{2}$, which was
13.5 and 12 days respectively. Thus the total amount of methotrexate taken and the timing of the drug doses appear to be independent factors in determining the development of malabsorption of xylose.

The finding of a functional though not symptomatic malabsorption of xylose implies that other substances may not be normally absorbed. Freeman-Narrod ${ }^{12}$ has shown that repeated oral administration of methotrexate may lead to a change in the absorption pattern of the drug itself from rapid to slow, with consequent lower peak concentrations, and that this may affect the efficacy of the drug's action on leukaemic cells. Venho ${ }^{13}$ has shown that methotrexate may cause malabsorption of other drugs such as phenobarbitone and isoniazid in rats. This may be an important unrecognised hazard in children with leukaemia who are given drugs for reasons other than their primary disease.

The Medical Research Council UKALL trials ${ }^{14}$ have shown that the timing of drug treatment is critical in determining the degree of immunosuppression and susceptibility to infection. This is supported by work in rats, which showed that doses of methotrexate separated by an interval of at least eight days have a considerably reduced effect on marrow suppression while still retaining their anti-leukaemic properties. ${ }^{15}$ The present study provides further evidence that regular methotrexate treatment given every seven days will cause greater toxicity than if it were more widely spaced. The current UKALL V trial is investigating the spacing of drug treatment, and may show whether the undoubted anti-leukaemic properties of methotrexate can be retained with reduced toxicity by separating the individual doses more widely.

We thank the nursing staff of Princess Chula ward for their willing assistance, and the staff of the biochemistry department for performing the xylose estimations.

AWC was supported by a Medical Research Council training fellowship.

Requests for reprints should be addressed to AWC.

\section{References}

${ }^{1}$ Mauer, A M, and Simone, J V, Cancer Treatment Reviews, 1976, 3, 17.

${ }^{2}$ Holland, J F, and Glidewell, O, New England fournal of Medicine, 1972 287, 769.

${ }^{3}$ Johns, D G, and Bertino, J R, in Cancer Medicine, ed J.F Holland and E Frei. Philadelphia, Lea and Febiger, 1973.

${ }^{4}$ Rolles, C J, et al, Lancet, 1973, 2, 1043.

${ }^{5}$ Medical Research Council's Working Party on Leukaemia in Childhood. Personal communication.

${ }^{6}$ Roe, J H, and Rice, E W, fournal of Biological Chemistry, 1948, 173, 507.

7 Shalet, S M, et al, Archives of Disease in Childhood, 1976, 51, 489.

${ }^{8}$ Small, M D, et al, American fournal of Digestive Diseases, 1959, 4, 700.

${ }^{9}$ Robinson, J W L, Antonioli, J A, and Vannotti, A, Biochemical Pharmacology, 1966, 15, 1479.

10 Trier, J S, Proceedings of the American Association for Cancer Research, 1961, 3, 273.

11 Trier, J S, Gastroenterology, 1962, 42, 295.

12 Freeman-Narrod, $\mathrm{M}$, in Methotrexate in the Treatment of Cancer, ed $\mathrm{R}$ Porter and E Wiltshaw, pp 17-21. Baltimore, Williams and Wilkins, 1962.

13 Venho, V M K, Acta Pharmacologica et Toxicologica, 1976, 38, 450.

${ }_{14}$ Maclennan, I C M, et al, British fournal of Haematology, 1976, 33, 179.

15 Harding, B, Culvenor, J, and Maclennan, I C M, British fournal of Cancer, $1977,35,40$.

(Accepted 30 September 1977) 